\title{
Erratum to: Potential of promotion of alleles by genome editing to improve quantitative traits in livestock breeding programs

Janez Jenko ${ }^{1}$, Gregor Gorjanc ${ }^{1}$, Matthew A. Cleveland ${ }^{2}$, Rajeev K. Varshney ${ }^{3}$, C. Bruce A. Whitelaw', John A. Woolliams ${ }^{1}$ and John M. Hickey ${ }^{1 *}$

After the publication of this work [1], we noticed that Figs. 1 and 2 were accidentally interchanged. The correct version order of Figs. 1 and 2 are provided here. The original article was corrected.

\begin{abstract}
Author details
'The Roslin Institute and Royal (Dick) School of Veterinary Studies, The University of Edinburgh, Easter Bush, Midlothian, Scotland, UK. ${ }^{2}$ Genus plc., 100 Bluegrass Commons Blvd., Suite 2200, Hendersonville, TN 37075, USA. ${ }^{3}$ International Crop Research Institute for the Semi-Arid Tropics (ICRISAT),

Patancheru, India.
\end{abstract}

Received: 23 July 2015 Accepted: 23 July 2015

Published online: 11 September 2015

\section{Reference}

1. Jenko J, Gorjanc G, Cleveland MA, Varshney RK, Whitelaw CBA,

Woolliams JA, et al. Potential of promotion alleles by genome editing to improve quantitative traits in livestock breeding programs. Genet Sel Evol. 2015;47:55.

\footnotetext{
* Correspondence: John.Hickey@roslin.ed.ac.uk

${ }^{1}$ The Roslin Institute and Royal (Dick) School of Veterinary Studies, The

University of Edinburgh, Easter Bush, Midlothian, Scotland, UK
}

Submit your next manuscript to BioMed Central and take full advantage of:

- Convenient online submission

- Thorough peer review

- No space constraints or color figure charges

- Immediate publication on acceptance

- Inclusion in PubMed, CAS, Scopus and Google Scholar

- Research which is freely available for redistribution

Submit your manuscript at www.biomedcentral.com/submit

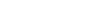




\begin{tabular}{|l|l|l|l|l|l|l|l|}
\hline \multicolumn{1}{|c|}{ Population } & Generations & Mutation & Selection & \\
\hline
\end{tabular}

PAGE - promotion of alleles by genome editing.

Fig. 1 Simulated scenarios for promotion of alleles by genome editing 


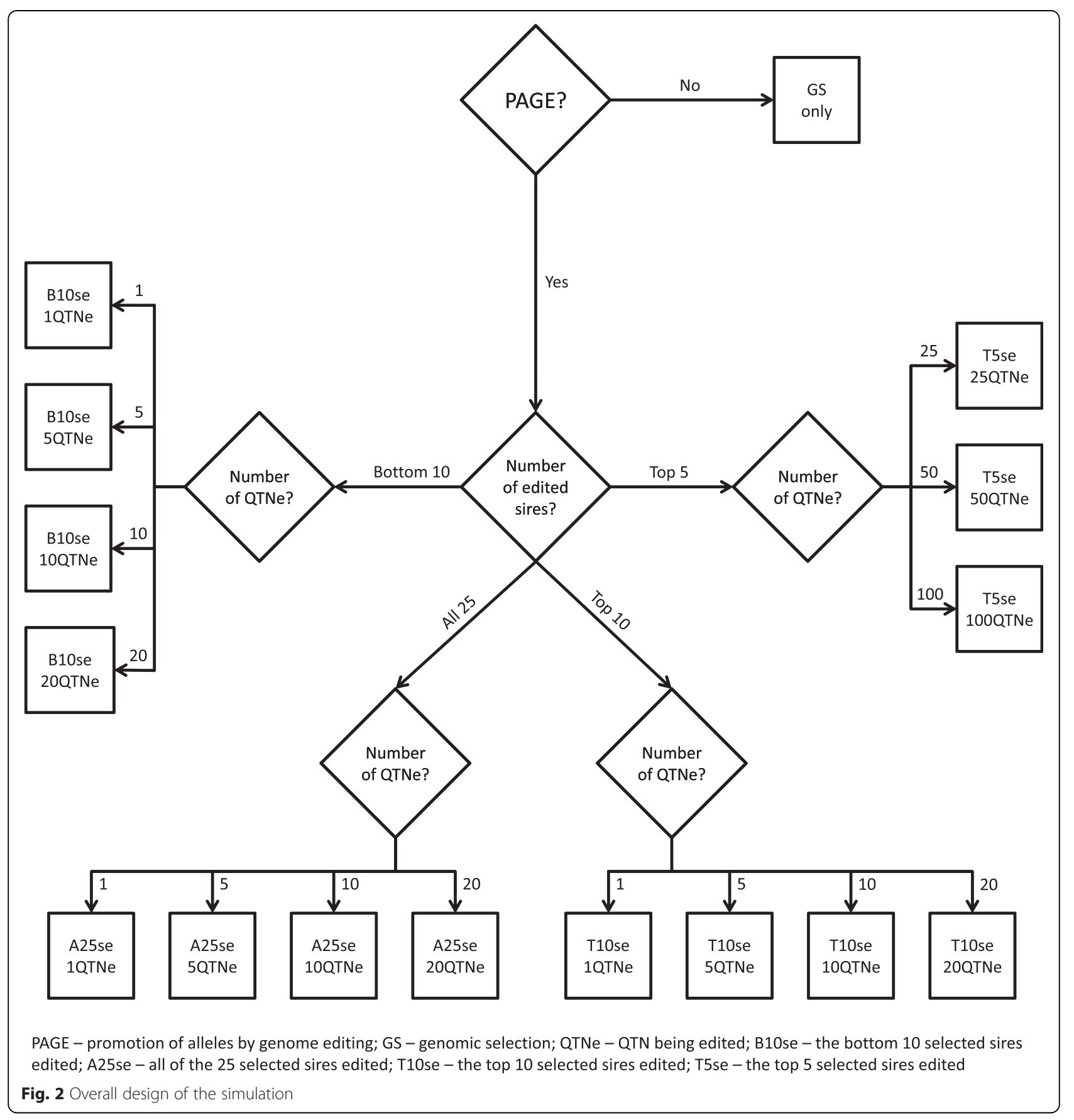

